\title{
Tungsten Fabricated by Laser Powder Bed Fusion
}

\author{
Pietro Rebesan ${ }^{1,2}$, Massimiliano Bonesso ${ }^{1,3}$, Claudio Gennari ${ }^{3}$, Razvan Dima ${ }^{1}$, Adriano Pepato ${ }^{1}$, and \\ Maurizio Vedani²
}

1Padova Division, National Institute for Nuclear Physics (INFN), Padova, Italy ${ }^{2}$ Department of Mechanical Engineering, Politecnico di Milano, Milano, Italy ${ }^{3}$ Department of Industrial Engineering, University of Padua, Padova, Italy

Received March 5, 2021; accepted April 5, 2021; published online April 28, 2021

\begin{abstract}
Additive Manufacturing ( $A M)$ is the process that allows the production of complex geometry and lightweight components. Thanks to the high density of refractory metals, AM could be a possible solution for their application in the aerospace field and for biomedical or future nuclear fusion devices. Yet, Laser Powder Bed Fusion (LPBF) of refractory metals as $\mathrm{Ta}, \mathrm{Mo}$, and $\mathrm{W}$ faces some challenges due to their main properties: high melting point, heat conductivity, and susceptibility to cracks.

The purpose of this study is to optimize the process parameters in order to produce high-density Tungsten parts by LPBF on an EOS M100 (maximum power of 170W). The characterization is performed through physical properties measurements and microstructural analysis. Single Scan Tracks (SSTs) are produced on the top surfaces of Tungsten blocks to evaluate the process parameters that give regular-shape and continuous melt-pools. Both analytical and experimental optimizations of process parameters were performed. Micro-hardness measurements were done for dense bulk specimens. Finally, a description of susceptibility to cracks of additively manufactured Tungsten was performed.
\end{abstract}

Keywords: Laser Powder Bed Fusion (LPBF), Selective Laser Melting (SLM), Refractory metals, Tungsten, Cracks, Single Scan Tracks

\section{Tungsten hergestellt durch Laserpulverbett-Fusion}

Zusammenfassung: Additive Manufacturing (AM) ist der Prozess, der die Herstellung komplexer Geometrien und leichter Komponenten ermöglicht. Dank der hohen Dichte von Refraktärmetallen könnte AM eine mögliche Lösung

\section{P. Rebesan ( $\square)$}

Padova Division,

National Institute for Nuclear Physics (INFN),

Via Marzolo, 8,

35131 Padova, Italy

pietro.rebesan@pd.infn.it für deren Anwendung im Bereich der Luft- und Raumfahrt sowie für biomedizinische oder zukünftige Kernfusionsgeräte sein. Die Laserpulverbettfusion (LPBF) von feuerfesten Metallen, wie Ta, Mo und W, steht jedoch aufgrund ihrer Haupteigenschaften vor einigen Herausforderungen: hoher Schmelzpunkt, Wärmeleitfähigkeit und Rissanfälligkeit. Der Zweck dieser Studie ist die Optimierung der Prozessparameter, um ein hochdichtes Wolframteil durch LPBF auf einer EOS M100 (maximale Leistung von 170W) herzustellen. Die Charakterisierung erfolgt durch Messungen der physikalischen Eigenschaften und Mikrostrukturanalyse. Single Scan Tracks (SSTs) werden auf den oberen Oberflächen von Wolframblöcken erzeugt, um die Prozessparameter zu bewerten, die regelmäßig geformte und kontinuierliche Schmelzpools ergeben. Es wurde sowohl eine analytische als auch eine experimentelle Optimierung der Prozessparameter sowie Mikrohärtemessungen für dichte Massenproben durchgeführt. Schließlich wurde die Anfälligkeit für Risse von additiv hergestelltem Wolfram beschrieben.

Schlüsselwörter: Laser Pulverbettfusion (LPBF), Selektives Laserschmelzen (SLM), Feuerfeste Metalle, Wolfram, Risse, Single-Scan-Spuren

\section{Introduction}

Refractory metals belong to the group of transition metals and are also called "ultra-high temperature materials". In addition to the high melting temperatures, they have properties, like high density, high thermal conductivity, and excellent corrosion resistance, that make them suitable for many applications [1]. For example, Tungsten is a promising candidate for nuclear fusion devices [2]; the proliferation of human osteoblast is much higher on tantalum compared to the most commonly used Ti-6Al-4V [3]; and finally for space and aerospace applications in order to increase the temperature capabilities of devices [4]. 
Tungsten produced by the laser powder bed fusion process is the subject of this contribution.

The traditional subtractive process for refractory metal tools is complicated and expensive, both for the waste of material that is removed and for the cost of tools suitable for hard metals, such as W, Ta, and Mo. For instance, the extremely high melting temperature, in addition to its high affinity towards oxygen at high temperatures, makes it difficult to process refractory metals components via conventional processing technologies like casting without a controlled atmosphere [5].

These reasons lead to the need of investigating Additive Manufacturing technologies and in particular the LPBF process. The production of refractory metals by Additive Manufacturing offers many advantages. The possibility of recycling the unmelted particles is one of the most important aspects for highly expensive powders like Ta. Due to their high melting point, the energy required to melt a volume of material is given by the focused energy of the laser beam which locally raises the temperature up to the melting point. AM is the only process that allows the production of complex geometry and lightweight refractory metals components, two important features for these kinds of materials, according to their high density and their possible applications in the aerospace field, and for biomedical or future nuclear fusion devices. Yet, selective laser melting of $\mathrm{W}$ faces some challenges due to its main properties: high melting point, heat conductivity, and susceptibility to cracks.

In this study, the optimization of the main process parameters in order to obtain Tungsten fully-dense components is performed and the susceptibility of $\mathrm{W}$ components produced by SLM to crack is described.

\section{Material and Methods}

\subsection{Powder and System}

For the optimization of the main process parameters, cubic samples in additively manufactured $\mathrm{W}$ were produced using an EOS M100 DMLS system by Electro-Optical Systems Gmbh. (EOS). The M100 machine is equipped with a $200 \mathrm{~W}$ $\mathrm{Yb}: Y A G$ laser with a wavelength of $1064 \mathrm{~nm}$ and a $40 \mu \mathrm{m}$ Gaussian spot diameter.

High purity Tungsten (99.9\%) raw material utilized for this study were highly spherical powders TEKMAT ${ }^{\mathrm{TM}} \mathrm{W}-25$. Plasma densification and spheroidization were done by Tekna Advanced Materials Inc. W powders have a particle size distribution of $D_{10}=10 \mu \mathrm{m}, D_{90}=25 \mu \mathrm{m}$.

The LPBF process was performed under Ar atmosphere. The oxygen content in the building chamber was about $0.1 \%$. Before printing began, the platform was preheated to $80^{\circ} \mathrm{C}(353 \mathrm{~K})$.

\subsection{Process Parameters}

The optimization of the main process parameters, such as laser power, scanning speed, and hatching distance, was performed in order to obtain fully dense components. W samples were built using a carbon steel substrate.

Two strategies were adopted in order to find the optimal process parameters: the analytical starting approach and the experimental confirmation test. Considering that the main feature of this refractory metal is the high melting point, some preliminary calculations were done in order to narrow the window of possible process parameters related to the melting of the powder bed [6]. Single Scan Track (SST) analyses were performed to observe the influence of the main process parameter related to the melting of the material, laser power, and scanning speed. Thirty-two SSTs were produced on the top surfaces of sixteen blocks $(8 \mathrm{~mm} \times 8 \mathrm{~mm} \times 8 \mathrm{~mm})$, combining four laser power values with eight scanning speed values. The production of blocks and SSTs were done in only one step. For the block production, the laser power was fixed to $170 \mathrm{~W}$, the scanning speed and hatching distance were in the range of $400-800 \mathrm{~mm} / \mathrm{s}$ and $0.04-0.07 \mathrm{~mm}$, respectively.

The scanning strategy chosen for $\mathrm{W}$ production was the bidirectional pattern with a $67^{\circ}$ rotation between adjacent layers in order to cut down the residual stress as much as possible. The stripes were scanned always in the opposite direction to the argon flow to minimize the presence of sparks and droplets of molten metal on the powder bed that has not yet been melted. The layer thickness $(t)$ selected was $20 \mu \mathrm{m}$ in order to guarantee a good bonding between consecutive layers. Considering the extremely high melting point of Tungsten, this layer thickness allows the homogeneous melting of the powder bed, and the re-melting of previous layers could result in a possible reduction of lack of fusion and delamination.

When the SLM process was concluded, the samples were detached from the platform by a wire Electrical Discharge Machine (EDM - SODICK AQ 750 LH).

\subsection{Characterization}

The flowability of $\mathrm{W}$ powder was measured with standard test methods for the flow rate of metal powders using the Hall Flowmeter funnel (according to ASTM B213-20). The test was performed five times with Method 2 (dynamic start to flow). The density of as-built W specimens was measured using the Archimedes' Principle (according to ASTM B962 - 17).

The surface morphology observation and microstructural analysis of blocks and SSTs as-fabricated were performed using a scanning electron microscope (Leica Cambridge Stereoscan LEO 440, Leica Microsystems S.r.I., MiIan, Italy). The SSTs thickness was measured with ImageJ image processing software. Tungsten samples were prepared with standard metallographic preparation and electrolytically etched with a solution of $10 \mathrm{~g}$ in $100 \mathrm{ml}$ of distilled water of sodium hydroxide $(\mathrm{NaOH})$ at $2 \mathrm{~V}$ for $15 \mathrm{~s}$. Microhardness measurements were performed on a Leitz Miniload 2 (Leica Microsystem S.r.l., Milan, Italy) microhardness tester with $200 \mathrm{~g}$ load. The measurement uncertainty for the flowability test, micro-hardness, was calculated as the standard deviation on the measurement, while, 
Fig. 1: SEM images of the Single Scan Tracks (SSTs) obtained using different scan laser Power (P) and Scan Speed ( $v$ )

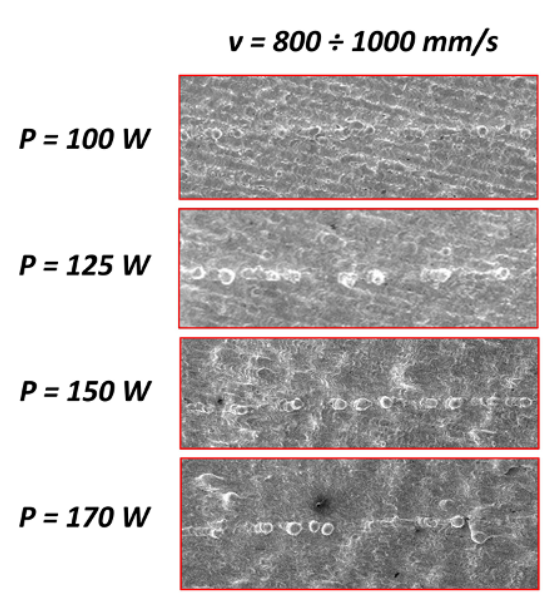

Droplet - Not melted
$500 \div 700 \mathrm{~mm} / \mathrm{s}$
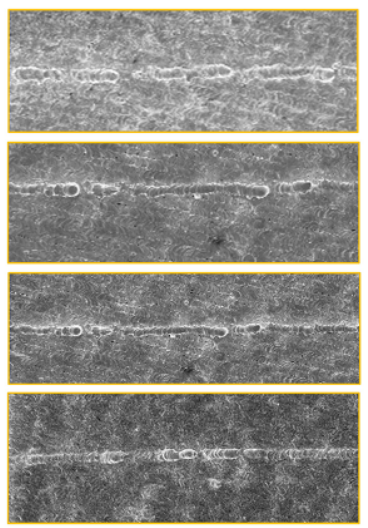

Fragmented - Irregular

\section{$v=200 \div 400 \mathrm{~mm} / \mathrm{s}$}

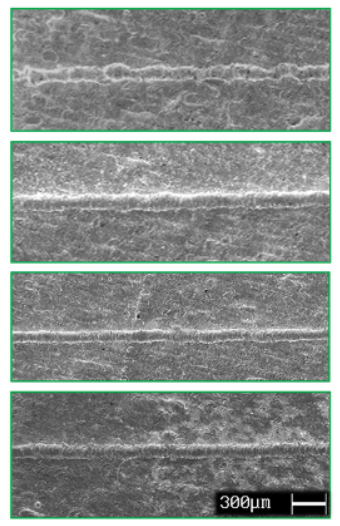

Continuous - homogeneous for the density measurement, the uncertainty was calculated with the Kline \& McClintoc formulation [7].

\section{Result and Discussion}

\subsection{Powder Characterization}

The powder morphology plays an important role in additively manufactured $\mathrm{W}$ production. Lower part density $\left(16 \mathrm{~g} / \mathrm{cm}^{3}\right)$ was produced in the study of Zhou et al. [8], where the raw material was $\mathrm{W}$ powder with an irregular shape. Wang et al. [9] made a comparison between two different morphologies, polyhedral and spherical powders, obtaining a density of $84 \%$ and $96 \%$ of the theoretical density. Also Tan et al. [6] confirmed the importance of the spherical powder. After a parameter optimization, specimens with high density values of $19.01 \mathrm{~g} / \mathrm{cm}^{3}$ (98.5\% of TD) were produced.

The particle size distribution (PDS) has a strong influence on laser absorption and on track formation during the SLM process. Zhang et al. [10] demonstrated that the powder layer absorptivity is strongly dependent on the PSD. The powder-to-laser absorptivity is 0.6030 when the particle diameter is in the range of $5-15 \mu \mathrm{m}$, it diminished up to 0.4986 in the range of $15-45 \mu \mathrm{m}$. On the other hand, the PSD influences the powder flowability, which can affect powder bed particle distribution during the process [11]. The flowability test performed with Method 2 (dynamic start to flow) gives a flow rate of $12.4 \pm 0.5 \mathrm{~s} / 50 \mathrm{gr}$ for Tungsten powder.

Although there was no flow with Method 1 (static start to flow) of the powder during the test with the Hall Flowmeter, the powder was still well distributed on the platform, also thanks to the use of a recoater with a metal blade.

\subsection{Selective Laser Melted Tungsten}

Fig. 1 shows SEM images of the Single Scan Tracks (SSTs) produced on the top surface of the Tungsten blocks using different scan laser power $(P)$ and scan speed $(v)$. In the melting of Tungsten powder, the SSTs production gives an immediate and effective response if the energy supplied is sufficient to melt the powder bed. Four values were chosen
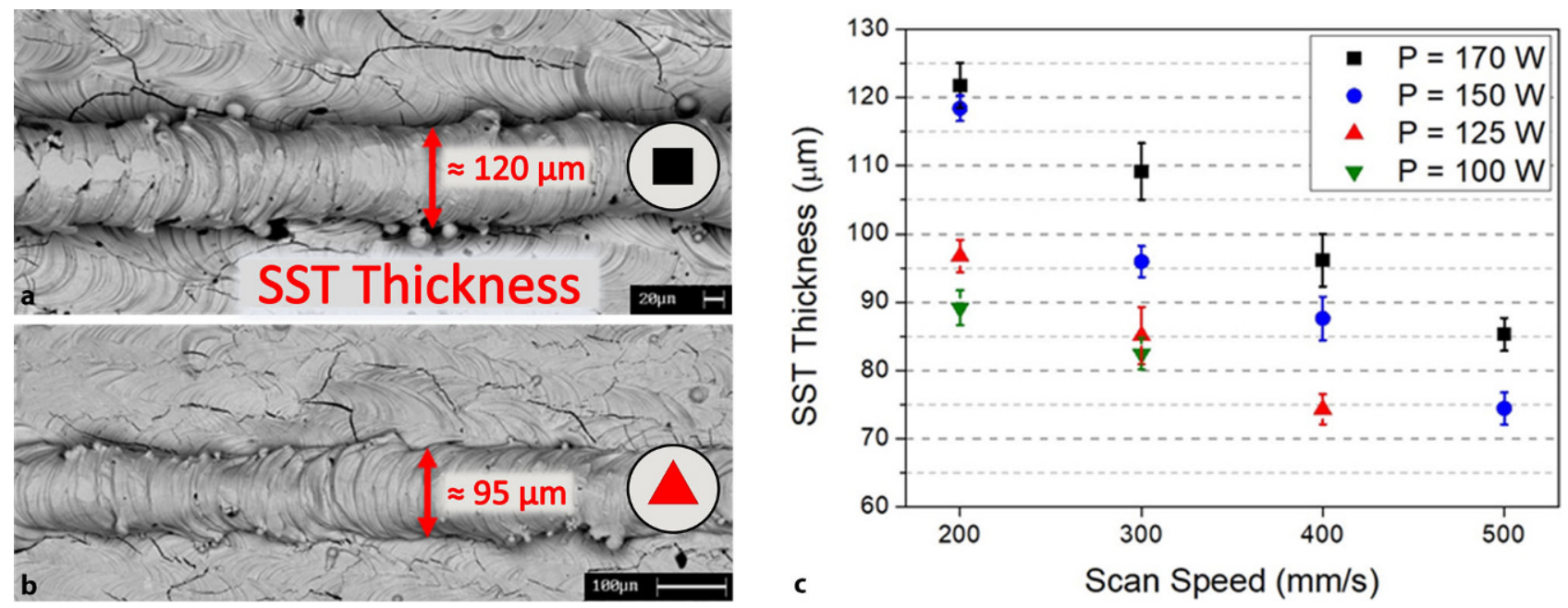

Fig. 2: a, b SEM images of SSTs used for width measure with ImageJ; c Thickness of continuous SSTs as a function of scan speed 
for laser power $(100,125,150,170 \mathrm{~W})$. For each laser power value listed, the scanning speed was set at 200,300, 400, 500, 700, 800, 900, $1000 \mathrm{~mm} / \mathrm{s}$. Fig. 1 shows the important role of the scan speed in the production of SSTs. With scan speeds included in the range of $800-1000 \mathrm{~mm} / \mathrm{s}$, it can be observed that the production of a melt track does not take place, but only the formation of W drops is visible, which are more evident at the higher powers. Another significant range is from 500 to $700 \mathrm{~mm} / \mathrm{s}$, where fragmented and irregular SSTs were melted by the laser during the process except for the highest value of laser power (170W). Finally, the range of $200-400 \mathrm{~mm} / \mathrm{s}$ (and also $500 \mathrm{~mm} / \mathrm{s}$ for the laser power of $170 \mathrm{~W}$ ) is the range in which the single tracks were continuous and homogeneous.

The effect of laser power in this successful production is related to the width of the tracks (Fig. 2).

If the effective power increases, the volume of the molten pool increases in turn, while the viscosity decreases, causing melt hydrodynamics (driven by Marangoni effect) to become the most important factor. When the scanning speed decreases, the heat affected zone becomes larger. For this reason, the melt pool involves more powder from its boundaries [12]. Fig. 2 shows the quantification of continuous and homogeneous Single Scan Track thickness as a function of the laser scanning speed, considering the different laser powers adopted. It can be seen from the graph of Fig. 2c that the thickness of the SSTs is strongly correlated to the laser power, with the same scanning speed chosen. The evaluation of SSTs morphology and the trend of data related to their thickness, in addition to the test of block fabrication, give important information in the choice of parameters for fully dense component production and also to produce an intact contour, thin walls, and lattice structures.

The parameter optimization in order to produce fully dense Tungsten blocks started with the analytic method proposed by Tan et al. [6]. These calculations are based on $\mathrm{Q}_{\mathrm{p}}\left(\mathrm{J} / \mathrm{mm}^{3}\right)$, which is the energy required to melt the volume of material (also called Volume Energy Density). The estimation of this energy has been calculated with Eq. 1:

$$
Q_{p}=\rho c_{p}\left(T_{m}-T_{0}\right)+\rho L_{f}
$$

\begin{tabular}{|lll|}
\hline $\begin{array}{l}\text { TABLE } 1 \\
\text { Physical properties used for theoretical calculation of } \\
\mathbf{Q}_{\mathbf{p}} \text { and } \mathbf{Q}_{\mathbf{v}}\end{array}$ & Value & Unit \\
\hline Physical Properties & 19.25 & $\mathrm{~g} \cdot \mathrm{cm}-3$ \\
\hline Density $(\rho)$ & 132 & $\mathrm{~J}(\mathrm{~kg} \cdot \mathrm{K})^{-1}$ \\
\hline Specific Heat $\left(c_{p}\right)$ & $3693(3420)$ & $\mathrm{K}\left({ }^{\circ} \mathrm{C}\right)$ \\
\hline Melting Point $\left(t_{m}\right)$ & $353(80)$ & $\mathrm{K}\left({ }^{\circ} \mathrm{C}\right)$ \\
\hline Initial Temperature $\left(t_{0}\right)$ & $2.20 \times 10^{5}$ & $\mathrm{~J} \cdot \mathrm{kg}-1$ \\
\hline Latent Heat of Fusion $\left(L_{f}\right)$ & 0,56 & {$[10]$} \\
\hline Laser Absorptivity $(\alpha)$ & 20 & $\mu \mathrm{m}$ \\
\hline Laser Beam Radius $\left(r_{l b}\right)$ & 40 & $\mu \mathrm{m}$ \\
\hline Melt Pool Radius $\left(r_{m}\right)$ & 20 & $\mu \mathrm{m}$ \\
\hline Layer Thickness $\left(I_{t}\right)$ & & \\
\hline
\end{tabular}

The physical properties used for the theoretical calculation of $Q_{p}$ are listed in Table 1.

The volumetric laser energy per unit volume $Q_{v}\left(\mathrm{~J} / \mathrm{mm}^{3}\right)$ of Tungsten powders can be determined from the expression as follows:

$$
\begin{aligned}
& Q_{V}=\frac{\pi r_{l b}^{2} E_{i n} \Delta t}{V_{m}} \\
& E_{i n}=\frac{2 \alpha P}{\pi r_{l b}^{2}}\left(1-e^{2}\right)(1-0.2)
\end{aligned}
$$

Where $E_{\text {in }}\left(\mathrm{W} / \mathrm{mm}^{2}\right)$ (Eq. 3) is the effective energy used for melting the powders, obtained from the average laser energy flux, which is the function of laser absorptivity $(\alpha)$, laser Power (P), and laser beam radius $\left(r_{l b}\right)$. In the $E_{i n}$ calculation, also the energy lost by convection, radiation, and evaporation (total heat loss $=20 \%$ ) [13] is considered. $\Delta t$ is the laser exposure time and is a function of the scan speed $(v)$ and laser beam radius $\left(r_{l b}\right) . V_{m}$ is the effective volume of the molten pool. The melt pool geometry is simplified as a part of a sphere, an approximation that is also confirmed by Bajaj's simulation studies [14], mainly due to the thermal properties of the refractory metal. The radius of the melt track is estimated twice as the $r_{l b}$, considering roughly the minimum width of the SSTs measured (average of about $80 \mu \mathrm{m}$ ) as shown in the diagram of Fig. 2. The laser melting depth was considered equal to double of the layer thickness $\left(I_{t}\right)$ in order to guarantee adhesion between one layer and the next thanks to re-melting. Moreover, re-melting decreases the possibility of forming the balling phenomenon due to rapid solidification and of reducing thermal stresses.

The second part of Table 1 lists also the geometrical parameters of the melting zone, the laser and powder parameters. Compared to the work proposed by Tan et al. [6], the value of the absorptivity is not that of the flat material (0.41), but the one calculated by Zhang et al. [10], chosen conservatively considering the maximum value $D_{90}$ of the PSD used $\left(D_{90}=25 \mu \mathrm{m}\right)$.

Theoretically, in order to completely melt the powders, the volumetric laser energy per unit volume has to be greater than the energy required to melt a volume of material $\left(\mathrm{Q}_{v}>\mathrm{Q}_{\mathrm{p}}\right)$.

The experimental test was performed with the laser power fixed at $170 \mathrm{~W}$ and four different scan speeds set at $400,500,600,800 \mathrm{~mm} / \mathrm{s}$. For all four combinations of parameters, $Q_{v}>Q_{p}$ is widely satisfied, as illustrated in the results of the calculations in Table 2, even if the $\mathrm{Op}$ value of $\mathrm{W}$ is high, because of the high melting point and density,

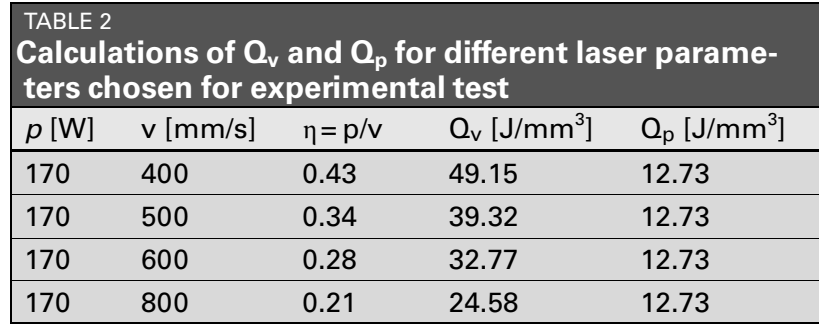




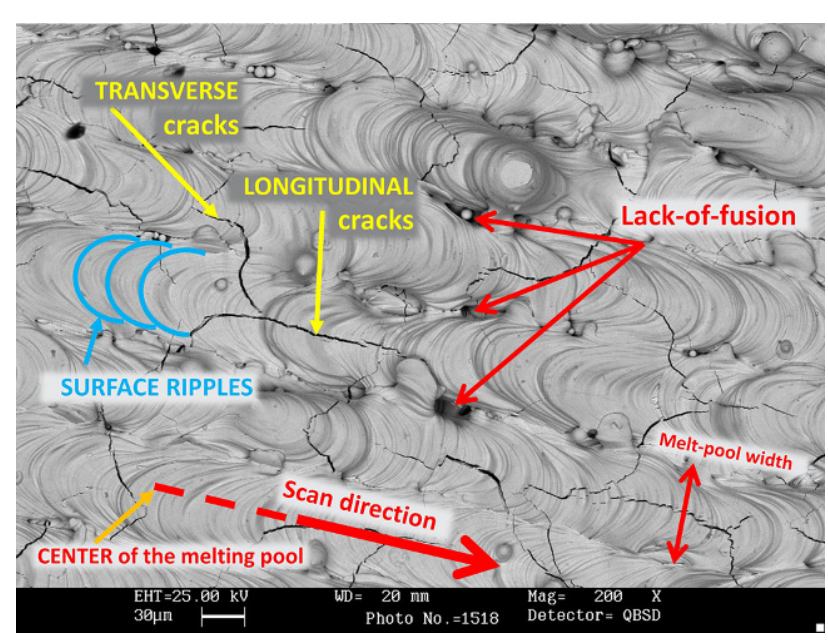

Fig. 3: SEM image of block surface with hatching distance of $0.7 \mathrm{~mm}$. Details on surface morphology and cracks type

resulting in large temperature gradient and residual stress [15].

The production of Tungsten blocks was performed with four different values of hatching distance from 0.04 to $0.07 \mathrm{~mm}$. The choice of this range of hatching distance was based on some considerations of machine parameters as the laser beam radius $\left(r_{l b}\right)$ and some of the main properties of Tungsten.

The dynamic viscosity $\mu$ of pure Tungsten was high because of the high melting point, high surface tension, and cohesive energy $[16,17]$. This leads to a low flowability of the melt pool. When the overlap between two consecutive scan tracks (hatching distance- $h_{d}$ ) is insufficient, there is the possibility of formation of defects, also called lack-offusion (LoF), as shown in Fig. 3. For this reason, the choice of the hatching distance was in the range of $0.04 \div 0.07 \mathrm{~mm}$, where 0.04 is the value of laser spot diameter $(40 \mu \mathrm{m})$. This should guarantee the overlap between consecutive scan tracks, even with a re-melting of at least half of the melting track.

The choice of such low hatching distances was beneficial as can be seen from the density measurements with the Archimedes' method, shown in the diagram of Fig. 4b. For scan speed values in the range $400-600 \mathrm{~mm} / \mathrm{s}$, the density measured was higher than $99 \%$, with a maximum of $99.61 \pm 0.5 \%$ for a scan speed of $600 \mathrm{~mm} / \mathrm{s}$.

A micro-mechanical characterization of the selective laser melted Tungsten was performed by an indentation test. The Vickers micro-hardness was measured on the specimens with a higher density, obtained with a scan speed of 400,500 , and $600 \mathrm{~mm} / \mathrm{s}$ and the hatching distance of $0.04 \mathrm{~mm}$. The same results were found for these three samples, with an average of $420 \mathrm{HV}$ and a standard deviation of 13.5. The result is in line with the hardness found by Wen et al. [17] and a greater hardness compared to conventional SPS processed Tungsten (in the range of $320 \div 400 \mathrm{HV}$ ) [18].

\subsection{Susceptibility to Crack}

Tungsten specimens show a typical behaviour of this refractory metal produced by LPBF process: high cracking tendency. As shown in Fig. 3, which displays some details on surface morphology and crack types on a W specimen, cracks grow by a certain regulation and are distributed homogenously on the surface of the samples. Thanks to the scheme proposed in Fig. 3, it is possible to define two kinds of cracks. The longitudinal ones, which initiate and propagate along the centre of the melt-pool, and the transverse cracks that are perpendicular to the surface ripples generated by the laser during the continuous scanning. Longitudinal cracks are linear and fragmented with a length between 30 and $100 \mu \mathrm{m}$. Transverse cracks are shorter and have an "S"-shape. They exactly follow the shape of the grain boundary, as can be seen from the SEM images of
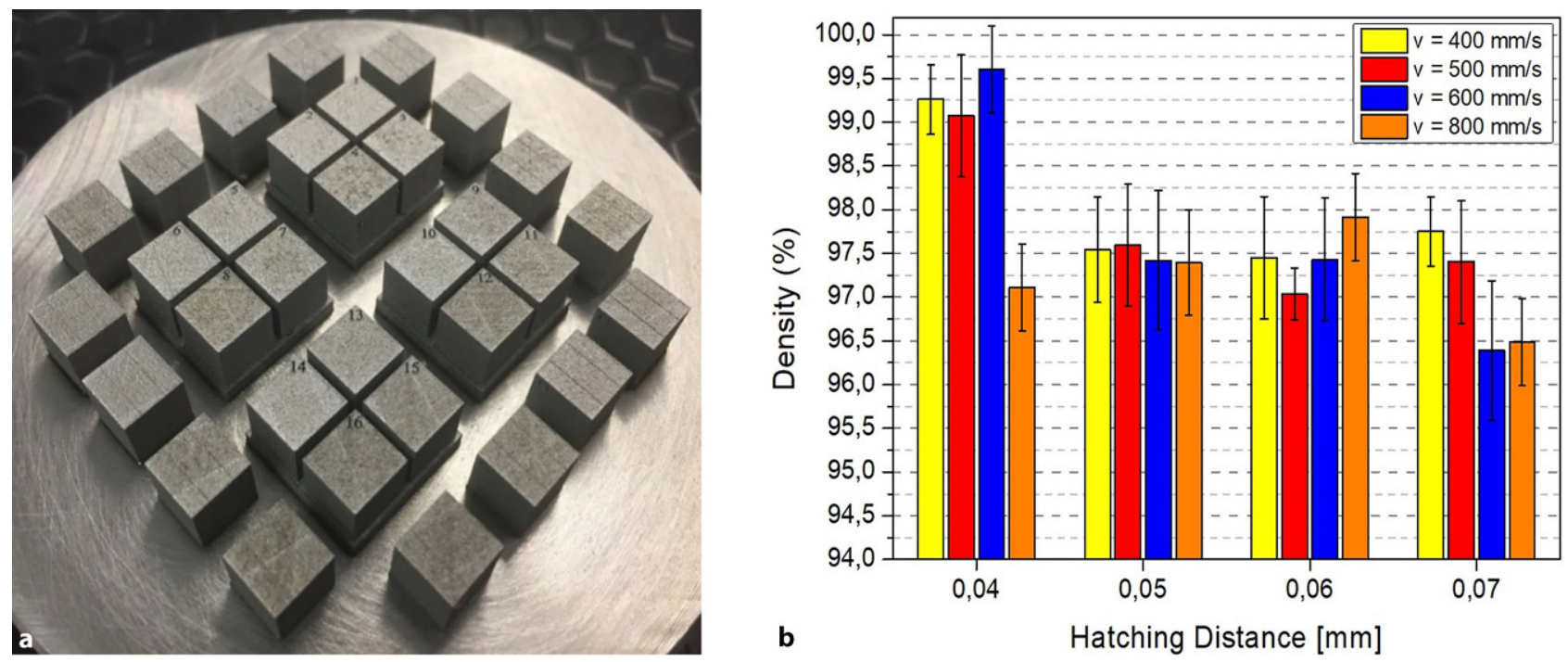

Fig. 4: a W blocks; b Density measured with Archimedes' method as function of hatch distance (hd) at different scan speed ( $v$ ) 
Fig. 5: a SEM image of W electrolytically etched sample displaying a crack network; b SEM Image of Mo sample displaying a magnification of grainboundaries and micro-cracks

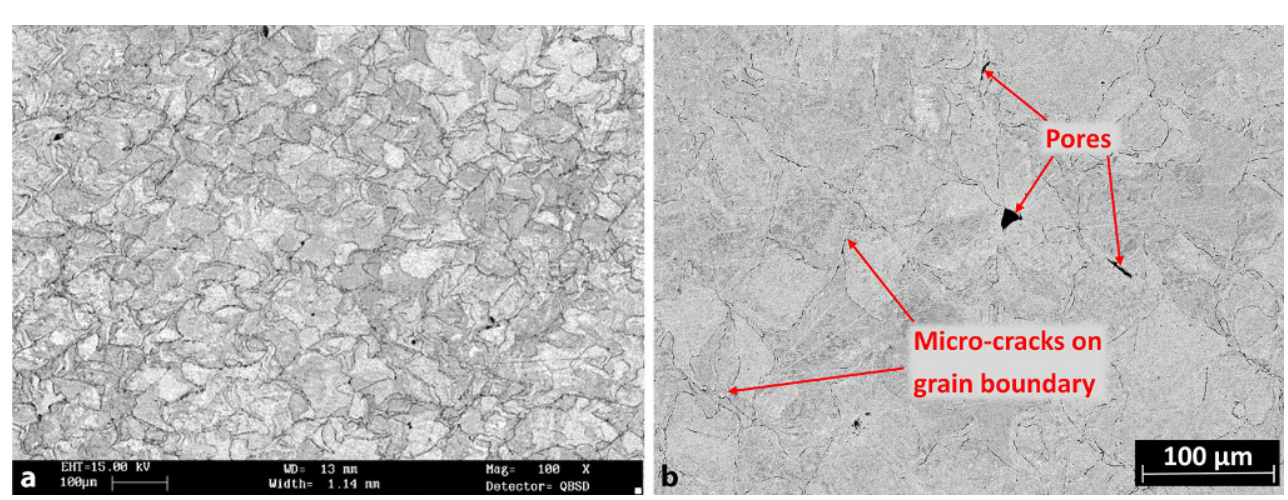

Fig. 5a showing the surface of the Tungsten sample after polishing and electrolytical etching.

The extensive cracking observed in additively manufactured Tungsten is the result of the thermal stresses arising during rapid solidification or recrystallization [19]. As the temperature drops below the ductile to brittle transition temperature (DBTT), the residual stress rises above the yield strength in the brittle material, resulting in a crack formation. Micro-cracks that we can see in the SEM images of Fig. $5 \mathrm{~b}$ are like the intergranular hot cracking in fusion welds in Tungsten. They originate from the aggregation of nanopores at the grain boundaries. Wang et al. [20] demonstrated that the formation of nanopores can be ascribed the boiling tungsten oxides (WOx) in the hot melting pool. These gas pores are pushed into grain boundaries during rapid solidification.

Wang et al. [21] observed that a differentiation of scanning strategy and re-melting cannot suppress the cracks, the only effect is a redistribution and change in the shape of defects. With a substrate preheating of $1000^{\circ} \mathrm{C}$, there is a reduction, but no complete mitigation of the microcracks [22]. Therefore, the only way to avoid cracking on SLM Tungsten is to eliminate or control the impurities. This is possible in two ways, the first one consists in avoiding any contact of the powder with an oxidizing atmosphere throughout the complete process route, the second way, more feasible, is by alloying it [23, 24].

\section{Conclusion}

In this contribution, the production of fully dense Tungsten specimens has been optimized starting from an analytical method. The process quality was quantified with the high value of density achieved of $99.6 \%$.

Continuous and homogeneous Single Scan Tracks (SSTs) of W were produced and measured. SSTs studying allows also to define the window of optimal laser power process parameters in order to produce intact contour, thin wall, and lattice structures.

The micro-hardness measured in fully dense Tungsten (420 HV) specimens was slightly higher than commercial and SPS Tungsten [25].

Tungsten processed by LPBF shows its tendency toward hot cracking. The strong presence of cracks leads to the con- clusion that this material is not suitable to be processed by SLM in the current form. The investigation is in progress to understand if there is the possibility to use them as traditional pure Tungsten components or rather in non-structural applications.

Funding. Open access funding provided by Politecnico di Milano within the CRUI-CARE Agreement.

Open Access This article is licensed under a Creative Commons Attribution 4.0 International License, which permits use, sharing, adaptation, distribution and reproduction in any medium or format, as long as you give appropriate credit to the original author(s) and the source, provide a link to the Creative Commons licence, and indicate if changes were made. The images or other third party material in this article are included in the article's Creative Commons licence, unless indicated otherwise in a credit line to the material. If material is not included in the article's Creative Commons licence and your intended use is not permitted by statutory regulation or exceeds the permitted use, you will need to obtain permission directly from the copyright holder. To view a copy of this licence, visit http://creativecommons.org/licenses/by/4.0/.

\section{References}

1. Shabalin, I. L.: Ultra-High Temperature Materials I, A Comprehensive Guide and Reference Book, Dordrecht: Springer, 2014

2. Hirai, T.; Panayotis, S.; Barabash, V.; Amzallag, C.; Escourbiac, F; Durocher, A.; Merola, M.; Linke, J.; Loewenhoff, T.; Pintsuk, G.; Wirtz, M.; Uytdenhouwen, I.: Use of tungsten material for the ITER divertor, Nuclear Materials and Energy, 9 (2016), pp 616-622

3. Wauthle, R.; Van Der Stok, J.; Yavari, S. A.; Van Humbeeck, J.; Kruth, J. P.; Zadpoor, A. A.; Weinans, H.; Mulier, M.; Schrooten, J.: Additively manufactured porous tantalum implants, Acta Biomaterialia, 14 (2015), pp 217-225

4. Zhang, H.; Xu, W.; Xu, Y.; Lu, Z.; Li, D.: The thermal-mechanical behavior of WTaMoNb high-entropy alloy via selective laser melting (SLM): experiment and simulation, International Journal of Advanced Manufacturing Technology, 96 (2018), pp 461-474

5. Balla, V. K.; Bodhak, S.; Bose, S.; Bandyopadhyay, A.: Porous tantalum structures for bone implants: Fabrication, mechanical and in vitro biological properties, Acta Biomaterialia, 6 (2010), pp 3349-3359

6. Tan, C.; Zhou, K.; Ma, W.; Attard, B.; Zhang, P.: Selective laser melting of high-performance pure tungsten: parameter design, densification behavior and mechanical properties, Science and Technology of Advanced Materials, 6996 (2018), pp 1-11

7. Kline, S. J.; McClintock, F. A.: Describing uncertainties in singlesample experiments, Mechanical Engineering, 75(1953), no 1, pp 3-8

8. Zhou, X.; Liu, X.; Zhang, D.; Shen, Z.; Liu, W.: Balling phenomena in selective laser melted tungsten, Journal of Materials Processing Tech., 222 (2015), pp 33-42 
9. Wang, D.; Yu, C.; Zhou, X.; Ma, J.; Liu, W.; Shen, Z.: Dense Pure Tungsten Fabricated by Selective Laser Melting, Applied Sciences 2017. https://doi.org/10.3390/app7040430

10. Zhang, J.; Gu, D.; Yang, Y.; Zhang, H.; Chen, H.; Dai, D.; Lin, K.: Influence of Particle Size on Laser Absorption and Scanning Track Formation Mechanisms of Pure Tungsten Powder During Selective Laser Melting, Engineering, 5 (2019), pp 736-745

11. Spierings, A. B.; Voegtlin, M.; Bauer, T.; Wegener, K.: Powder flowability characterisation methodology for powder-bed-based metal additive manufacturing, Progress in Additive Manufacturing, 1 (2016), pp 9-20

12. Yadroitsev, I.; Bertrand, P.; Smurov, I.: Parametric analysis of the selective laser melting process, Applied Surface Science, 253 (2007), pp 8064-8069

13. Han, L.; Liou, F. W.; Musti, S.: Thermal behavior and geometry model of melt pool in laser material process, Journal of Heat Transfer, 127 (2005), pp 1005-1014

14. Bajaj, P.; Wright, J.; Todd, I.; Jägle, E. A.: Predictive process parameter selection for Selective Laser Melting Manufacturing: Applications to high thermal conductivity alloys, Additive Manufacturing, 27 (2019), pp 246-258

15. Tang, L.; Landers, R. G.: Melt pool temperature control for laser metal deposition processes-part I: Online temperature control, Jour-

nal of Manufacturing Science and Engineering, Transactions of the ASME, 132 (2010), pp 0110101-0110109

16. Gu, D.; Hagedorn, Y. C.; Meiners, W.; Meng, G.; Batista, R. J. S.; Wissenbach, K.; Poprawe, R.: Densification behavior, microstructure evolution, and wear performance of selective laser melting processed commercially pure titanium, Acta Materialia, 60 (2012), pp 3849-3860

17. Wen, S.; Wang, C.; Zhou, Y.; Duan, L.; Wei, Q.; Yang, S.: High-density tungsten fabricated by selective laser melting: Densi fi cation, microstructure, mechanical and thermal performance, Optics and Laser Technology, 116 (2019), pp 128-138

18. Liu, G. Y.; Ni, S.; Song, M.: Effect of indentation size and grain/subgrain size on microhardness of high purity tungsten, Transactions of Nonferrous Metals Society of China (English Edition), 25 (2015), pp 3240-3246

19. Budaev, V. P.; Martynenko, Y. V.; Karpov, A. V.; Belova, N. E.; Zhitlukhin, A. M.; Klimov, N. S.; Podkovyrov, V. L.; Barsuk, V. A.; Putrik, A. B.; Yaroshevskaya, A. D.; Giniyatulin, R. N.; Safronov, V. M.; Khimchenko, L. N.: Tungsten recrystallization and cracking under ITER-relevant heat loads, Journal of Nuclear Materials, 463 (2015), pp 237-240

20. Wang, D.; Wang, Z.; Li, K.; Ma, J.; Liu, W.; Shen, Z.: Cracking in laser additively manufactured $\mathrm{W}$ : Initiation mechanism and a suppression approach by alloying, Materials and Design, 162 (2019), pp 384-393

21. Wang, D. Z.; Li, K. L.; Yu, C. F.; Ma, J.; Liu, W.; Shen, Z. J.: Cracking Behavior in Additively Manufactured Pure Tungsten, Acta Metallurgica Sinica (English Letters), 32 (2019), pp 127-135

22. Müller, A.; Schlick, G.; Neu, R.; Anstätt, C.; Klimkait, T.; Lee, J.; Pascher, B.; Schmitt, M.; Seidel, C.: Additive manufacturing of pure tungsten by means of selective laser beam melting with substrate preheating temperatures up to $1000 \circ \mathrm{C}$, Nuclear Materials and Energy, 19 (2019), pp 184-188

23. Kaserer, L.; Braun, J.; Stajkovic, J.; Leitz, K. H.; Tabernig, B.; Singer, P.; Letofsky-Papst, I.; Kestler, H.; Leichtfried, G.: Fully dense and crack free molybdenum manufactured by Selective Laser Melting through alloying with carbon, International Journal of Refractory Metals and Hard Materials, 84 (2019), p. 105000

24. Omidvari, N.; Vrancken, B.; Lietaert, K.; Vanmeensel, K.; Vleugels, J.; Kruth, J.: Selective laser melting of tungsten and tungsten alloys, International Journal of Refractory Metals and Hard Materials 72 (2018), pp 27-32

25. Choi, J.; Sung, H. M.; Roh, K. B.; Hong, S. H.; Kim, G. H.; Han, H. N.: Fabrication of sintered tungsten by spark plasma sintering and investigation of thermal stability, International Journal of Refractory Metals and Hard Materials, 69 (2017), pp 164-169

Publisher's Note. Springer Nature remains neutral with regard to jurisdictional claims in published maps and institutional affiliations. 